\title{
Crystal Packing Studies, Thermal Properties and Hirshfeld Surface Analysis in the Zn(II) Complex of 3-Aminopyridine with Thiocyanate as Co-Ligand
}

\section{Divine Mbom Yufanyi ${ }^{*}$, Hubert Jean Nono², Amah Colette Benedicta Yuoh ${ }^{3}$, Che Dieudonne Tabong ${ }^{4}$, Wirsiy Judith ${ }^{3}$, Agwara Moise Ondoh ${ }^{5}$}

\author{
${ }^{1}$ Department of Fundamental Science, Higher Technical Teachers' Training College, The University of Bamenda, Bamenda, \\ Cameroon \\ ${ }^{2}$ Department of Chemical and Biological Engineering, National Higher Polytechnic Institute, The University of Bamenda, \\ Bamenda, Cameroon \\ ${ }^{3}$ Department of Chemistry, Faculty of Science, The University of Bamenda, Bamenda, Cameroon \\ ${ }^{4}$ Department of Chemistry, Higher Teacher Training College, The University of Bamenda, Bamenda, Cameroon \\ ${ }^{5}$ Department of Inorganic Chemistry, Faculty of Science, University of Yaounde I, Yaounde, Cameroon \\ Email: ^dyufanyi@yahoo.com
}

How to cite this paper: Yufanyi, D.M., Nono, H.J., Yuoh, A.C.B., Tabong, C.D., Judith, W. and Ondoh, A.M. (2021) Crystal Packing Studies, Thermal Properties and Hirshfeld Surface Analysis in the Zn(II) Complex of 3-Aminopyridine with Thiocyanate as Co-Ligand. Open Journal of Inorganic Chemistry, 11, 63-84.

https://doi.org/10.4236/ojic.2021.113005

Received: April 19, 2021

Accepted: July 5, 2021

Published: July 8, 2021

Copyright $\odot 2021$ by author(s) and Scientific Research Publishing Inc. This work is licensed under the Creative Commons Attribution International License (CC BY 4.0).

http://creativecommons.org/licenses/by/4.0/

\begin{abstract}
Reaction of zinc acetate, potassium thiocyanate and the ligand 3-ampy gave the discrete tetrahedral complex $\left[\mathrm{Zn}(\mathrm{NCS})_{2}(3 \text {-ampy })_{2}\right]$ in which 3 -ampy chelates in a monodentate fashion through its pyridine- $\mathrm{N}$ atom. It was characterized by single crystal X-ray diffraction, infrared, and elemental analysis. Density Functional Theory calculations were performed in order to gain insights into the role of weak molecular interactions in the complex that influence the self-assembly process and crystal packing. $\mathrm{X}---\mathrm{H}(\mathrm{X}=\mathrm{H}, \mathrm{C}, \mathrm{N}$ and $\mathrm{S})$ inter-actions. S-H interactions (30.2\%) were found to be the main interactions that hold the molecules in the crystal structure. Furthermore, the thermolysis of the complex was studied in order to evaluate whether it was suitable as a precursor for zinc sulphide.
\end{abstract}

\section{Keywords}

Aminopyridine, DFT Studies, Hirshfeld Surface, Thiocyanate, Zinc

\section{Introduction}

Sustained scientific interest in the coordination chemistry of N-heterocyclic ligands, in particular pyridine-based compounds, is due to the characteristic 
properties they impart to the complexes they form. Introduction of different substituents on these ligands can introduce diverse electronic, steric and conformational properties to both the ligand and the complexes thereof. Aminopyridine derivatives are rigid ligands that have received much attention in the synthesis of coordination compounds and coordination polymers due to their diverse coordination modes, properties and applications in Pharmacy, medicine, dyes, and also because they are suitable chelating ligands in a variety of inorganic and organometallic applications. In the presence of potentially bridging pseudohalides, such as thiocyanate, azide, dicyanamide etc., coordination polymers and 3D structures have been achieved [1]-[7].

Amongst these ligands, 3-aminopyridine, a potential bidentate ligand with two nitrogen donor atoms, which is used in the synthesis of drugs and dyes, has been explored [1] [3] [6] [8]-[19]. It can act as monodentate ligand by coordinating metal ions through the pyridyl $\mathrm{N}$-atom or, less likely, through the amino $\mathrm{N}$-atom. As a bidentate ligand, it coordinates through the pyridyl $\mathrm{N}$-atom and the amino N-atom [19]. Supramolecular structures of higher dimensionality have been achieved with this ligand in the monodentate coordination mode and the pendant amino group serving as potential $\mathrm{H}$-bond donor or acceptor sites [17] [19].

The coordination chemistry of thiocyanate ions is still a subject of intense scientific interest due to their diverse coordination modes (terminal and bridging) which eventually results in several structures with varying topologies and potential optical, photoluminescent and magnetic applications [3] [5] [20].

Crystal packing and stability of these complexes is a function of the geometry of the complex and the substituents on the pyridine ring, which can lead to different types of intermolecular forces, stacking interactions and non-covalent interactions. The importance of non-covalent interactions in molecular crystals and biomolecules has led to a surge in the investigation of these interactions in nitrogen-containing heterocycles [19] [21]. Such studies are relevant as they assist in the design of novel supramolecular structures as well as a better elucidation of their solid state crystal packing.

Considering the coordination ability and properties of zinc, 3-aminopyridine and $\mathrm{SCN}^{-}$, and in continuation of our interest in the synthesis of coordination polymers of heterocyclic $\mathrm{N}$-donor ligands with pseudohalide co-ligands, which have been found to have interesting structures and properties [22] [23], we report the synthesis of a $\mathrm{Zn}$ (II) complex of 3-aminopyridine with thiocyanate as co-ligand. While aiming at the $1 \mathrm{D}$ coordination polymer, we obtained the structure reported herein, which is known in the literature [11]. However, in addition to the crystal structure, we include the description of a simple and cost-effective synthetic method as well as its spectroscopic and thermal properties. Although several aminopyridine structures have been reported, only a few have focused on the influence of non-covalent and stacking interactions on the crystal packing [15] [16] [21] [24]. The investigation of non-covalent interactions and stacking interactions and their influence on crystal packing, as well as the analysis of the 
electron density, Hirshfeld surface and potential energy surface of the complex, is our contribution to this rapidly growing field.

\section{Experimental}

\subsection{Materials and Methods}

All chemicals and solvents were obtained from commercial sources and used as received.

\subsection{Synthesis of the Complex}

To a $10 \mathrm{~mL}$ aqueous solution of $\mathrm{Zn}\left(\mathrm{CH}_{3} \mathrm{COO}\right)_{2} \cdot 2 \mathrm{H}_{2} \mathrm{O}(0.367 \mathrm{~g} ; 2.0 \mathrm{mmol})$ was added a $5 \mathrm{~mL} \mathrm{MeOH}$ solution of 3-Ampy (0.188 g; $2.0 \mathrm{mmol})$. The mixture was stirred at ambient temperature for 15 minutes. To the mixture was added a $5 \mathrm{~mL}$ $\mathrm{MeOH}$ solution of $\mathrm{KSCN}$ ( $0.389 \mathrm{~g}$; $4 \mathrm{mmol})$. The resulting mixture was further stirred for 30 minutes after which a white precipitate was obtained. The precipitate was filtered, washed with $\mathrm{MeOH}$, air-dried, and weighed. The filtrate was allowed in a refrigerator at $4^{\circ} \mathrm{C}$ and colourless crystals were obtained. [Zn(3-ampy $\left.)_{2}(\mathrm{SCN})_{2}\right]$ : yield: $72.4 \%$. Element Anal. Calc. for $\mathrm{C}_{12} \mathrm{H}_{12} \mathrm{~N}_{6} \mathrm{~S}_{2} \mathrm{Zn}$ : C, 38.94; H, 3.25; N, 22.72. Found: C, 39.03; H, 2.93; N, 22.54. IR ( $\left.\mathrm{KBr} \operatorname{dics~cm} \mathrm{cm}^{-1}\right)$ : $3449(\mathrm{~m}), 3347(\mathrm{~m}), 2109(\mathrm{sh}), 2089(\mathrm{~s}), 1623(\mathrm{~m}), 1581(\mathrm{~m}), 1494(\mathrm{~m}), 1449(\mathrm{~m})$, $1354(\mathrm{~m}), 1137(\mathrm{~m}), 800(\mathrm{~m}), 697(\mathrm{~m}) 548(\mathrm{w})$.

\subsection{Characterization Techniques}

IR spectra: $\mathrm{KBr}$ pellets were prepared in a nitrogen-filled glove box and the spectra were recorded on a PerkinElmer System 2000 FTIR spectrometer in the range $400-4000 \mathrm{~cm}^{-1}$. Elemental analyses for $\mathrm{C}, \mathrm{H}$, and $\mathrm{N}$ were performed on a FlashEA1112 element analyser. Thermogravimetric (TG) and differential thermal analysis (DTA) curves, coupled with mass spectrometry, were obtained using a NETZSCH STA449F1 thermoanalyzer in a dynamic argon atmosphere (heating rate $10^{\circ} \mathrm{C} \cdot \mathrm{min}^{-1}$, flow rate $25 \mathrm{~mL} \cdot \mathrm{min}^{-1}$, aluminium oxide crucible, mass $20 \mathrm{mg}$, and temperature range from room temperature up to $900^{\circ} \mathrm{C}$ ).

\subsection{Data Collection and Structure Refinement}

X-ray data were collected with a GEMINI CCD diffractometer (Rigaku Inc.), $\lambda\left(\right.$ Mo- $\left.K_{\alpha}\right)=0.71073 \AA, T=130(2) \mathrm{K}, \omega$-scan rotation. Data reduction was performed with CrysAlis Pro including the program SCALE3 ABSPACK for empirical absorption correction [14]. All structures were solved by dual space methods with SHELXT-20xy [25]. Structure refinement was done with SHELXL-2018 [26] [27] by using full-matrix least-square routines against $F$. Hydrogen atoms and $\mathrm{NH}$ were located on difference Fourier maps calculated at the final stage of the structure refinement. The remaining hydrogen atoms of (2) were calculated on idealised positions using the riding model. The pictures were generated with the program Mercury [28]. CCDC 2075665 contains the supplementary crystallographic data for this paper. These data can be obtained free of charge via 
https://www.ccdc.cam.ac.uk/data_request/cif (or from the Cambridge Crystallographic Data Centre, 12 Union Road, Cambridge CB2 1EZ, UK; fax: (+44)1223336-033; or deposit@ccdc.cam.uk).

\subsection{DFT Calculations}

Calculations were performed on the complexes to gain further insights into the molecular interactions in the synthesized compound and to predict some of their electronic properties. A single molecule as well as a dimer of the complex was optimized without any symmetric constraints. The calculations on the single molecule were performed using DFT methods and two exchange-correlations functional [29]: the B3LYP that associates the Becke three parameter exchange functional [30] [31] and the Lee-Yan-Parr correlation functional [32] and the wB97XD which integrates a long-range correction term [33] [34]. wB97XD has the advantage being able to model with accuracy short-range and long-range interactions. The molecular orbitals of the studied molecule were described by a polarized and diffused triple split valence orbital Pople basis set $6-311++G(2 d, 2 p)$ [35]. This basis set has been polarized for all atoms to improve the flexibility of molecular orbitals [36]. The optimization process was based on the X-ray structure data, and making use of ultrafine integral and tight optimization criteron. The harmonic vibrational frequencies of the optimized geometry were calculated to ensure that no imaginary frequency was associated to the optimized molecule. The calculations on the dimer were performed using wB97XD/6-31++G(d,p) level of theory. Gaussian 09 Revision A.02 package [37] was used for all quantum calculations. The non-covalent interactions (NCI) such as hydrogen bond and van der Waals interactions were described by the Contreras-Garcia and collaborators approach referred to as non-covalent interactions index [38] [39]. The multiwfn software [40] was used for this purpose.

\section{Results and Discussion}

Different synthetic strategies with the same starting materials can lead to different products, or at times, similar products. While targeting the thiocyanonato-bridged polymeric Zinc complex with 3-Ampy, we rather obtained the molecular complex $\mathrm{Zn}(3 \text {-ampy })_{2}(\mathrm{SCN})_{2}$. However, the synthetic method is different from the solvothermal synthetic method for the same complex reported earlier [11].

\subsection{X-Ray Crystal Structure}

Single crystal X-ray structure analysis of the complex (Figure 1) revealed that it is the same as the $\mathrm{Zn}(3 \text {-ampy })_{2}(\mathrm{SCN})_{2}$ complex previously reported, but with a different orientation of the aminopyridine rings around the metal centre [11]. The complex crystallizes in the orthorhombic space group Pnma with $\mathrm{Z}=4$ and contains only one crystallographically independent $\mathrm{Zn}$ cation that is located, together with the two $\mathrm{SCN}^{-}$ions, on a mirror plane. The $\mathrm{Zn}$ cation is tetrahedrally 
coordinated by two terminal N-bonded thiocyanate anions and two monodentate (through the pyridine $\mathrm{N}$-atom) 3-aminopyridine ligands. The packing diagram is shown in Figure 2. Crystallographic data for the complex complex to that in the literature is presented in Table 1.

An interplay of weak intermolecular interactions and face to face $\pi^{-} \pi$ stacking interactions of coordinated 3-ampy moieties extend the structure into three dimensions.

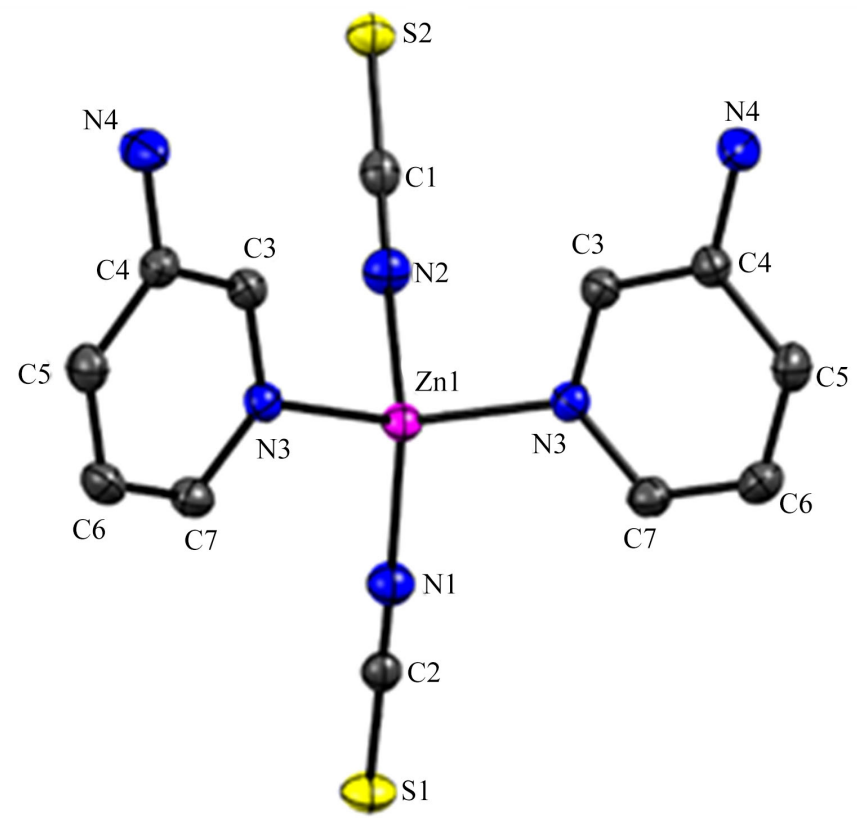

Figure 1. Molecular structure (seen along crystallographic a-axis) and atom-labelling scheme for the complex with ellipsoids drawn at $50 \%$ probability level. $\mathrm{H}$ atoms are omitted for clarity.

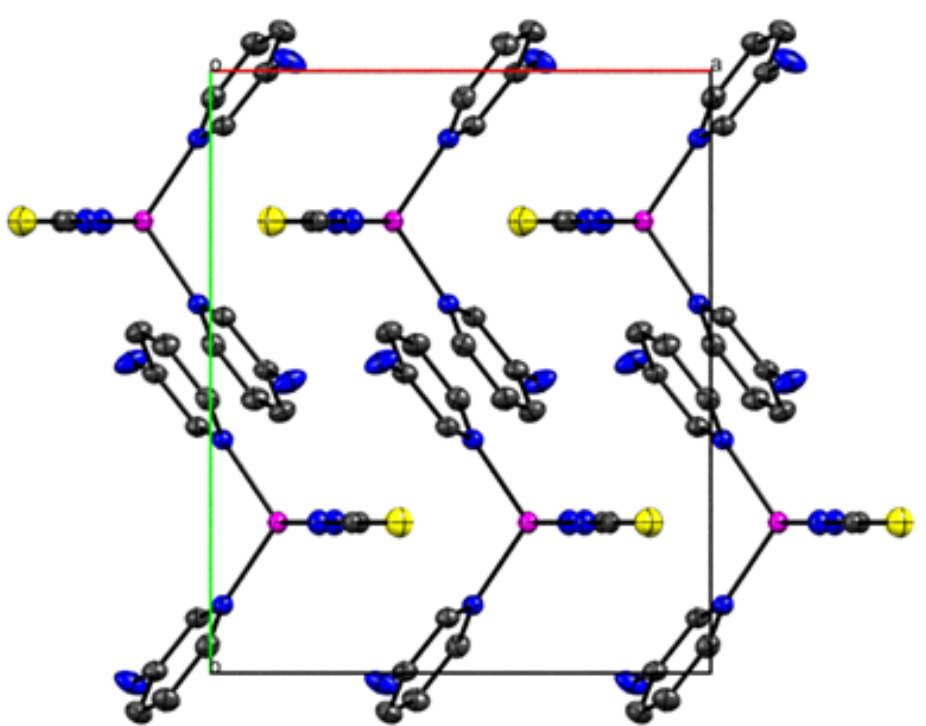

Figure 2. Packing diagram of the complex seen along the crystallographic c axis. 
Table 1. Comparative Crystallographic data and processing parameters of the complex.

\begin{tabular}{|c|c|c|}
\hline & $\mathrm{Zn}(3 \text {-ampy })_{2}(\mathrm{SCN})_{2}$ & $\mathrm{Zn}(3 \text {-ampy })_{2}(\mathrm{SCN})_{2}[11]$ \\
\hline Chemical formula & $\mathrm{C}_{12} \mathrm{H}_{12} \mathrm{~N}_{6} \mathrm{~S}_{2} \mathrm{Zn}$ & {$\left[\mathrm{Zn}(\mathrm{NCS})_{2}\left(\mathrm{C}_{5} \mathrm{H}_{6} \mathrm{~N}_{2}\right)_{2}\right]$} \\
\hline$M_{r}$ & 369.77 & 369.77 \\
\hline Crystal system, space group & Orthorhombic, Pnma & Orthorhombic, Pnma \\
\hline Temperature (K) & 130 & \\
\hline$a, b, c(\AA)$ & $10.0407(3), 12.1062(4), 12.6172(4)$ & $10.174(3), 12.312(3), 12.711(4)$ \\
\hline$V\left(\AA^{3}\right)$ & $1533.68(8)$ & $1592.2(8)$ \\
\hline$Z$ & 4 & 4 \\
\hline Radiation type & Mo $K a$ & Mo $\mathrm{K}$ radiation \\
\hline$\mu\left(\mathrm{mm}^{-1}\right)$ & 1.87 & \\
\hline Crystal size $(\mathrm{mm})$ & $0.50 \times 0.03 \times 0.01$ & \\
\hline Diffractometer & Xcalibur, Sapphire3, Gemini diffractometer & \\
\hline Absorption correction & Multi-scan & \\
\hline$T_{\min }, T_{\max }$ & $0.759,1.000$ & \\
\hline No. of measured, independent and observed $[I>2 \sigma(I)]$ reflections & $22,468,2782,2260$ & \\
\hline$R_{\text {int }}$ & 0.053 & \\
\hline$(\sin \theta / \lambda)_{\max }\left(\AA^{-1}\right)$ & 0.757 & \\
\hline$R\left[F^{2}>2 \sigma\left(F^{2}\right)\right], w R\left(F^{2}\right), S$ & $0.035,0.074,1.05$ & \\
\hline No. of reflections & 2782 & \\
\hline No. of parameters & 130 & \\
\hline No. of restraints & 0 & \\
\hline $\mathrm{H}$-atom treatment & All $\mathrm{H}$-atom parameters refined & \\
\hline$\Delta \rho_{\max }, \Delta \rho_{\min }\left(\mathrm{e} \AA^{-3}\right)$ & $0.42,-0.38$ & \\
\hline
\end{tabular}

\subsection{IR Spectroscopy}

The IR spectrum of the complex reveals characteristic bands for 3-ampy and the thiocyanate ligands. These bands are presented in Figure 3. The medium strong vibrations at 3347 and $3449 \mathrm{~cm}^{-1}$ are assigned to $v_{\mathrm{s}}\left(\mathrm{NH}_{2}\right)$ and $v_{\mathrm{as}}\left(\mathrm{NH}_{2}\right)$ vibrations of the $\mathrm{NH}_{2}$ group, respectively. The medium peak at $1581 \mathrm{~cm}^{-1}$ is assigned to $\mathrm{NH}_{2}$ deformation vibration [19]. The very strong $\mathrm{C} \equiv \mathrm{N}$ asymmetric stretching vibrations of the $\mathrm{SCN}^{-}$are observed at $2109 \mathrm{~cm}^{-1}$ in the spectrum of the complex, indicating that it has taken part in bonding [17]. The $v_{\mathrm{C}=\mathrm{N}}$ stretching modes of the pyridine ring shifted from 1595 to $1623 \mathrm{~cm}^{-1}$ in the spectrum of the complex, indicating its participation in bonding. The strong, well resolved and sharp absorption bands found in the region of $1494-1000 \mathrm{~cm}^{-1}$ in the spectrum of the complex are assigned to the aryl $\mathrm{C}-\mathrm{H}$ stretching vibrations of the coordinated pyridine ring. The $\mathrm{Zn}-\mathrm{Npy}$ stretching mode is present at about $548 \mathrm{~cm}^{-1}$. 


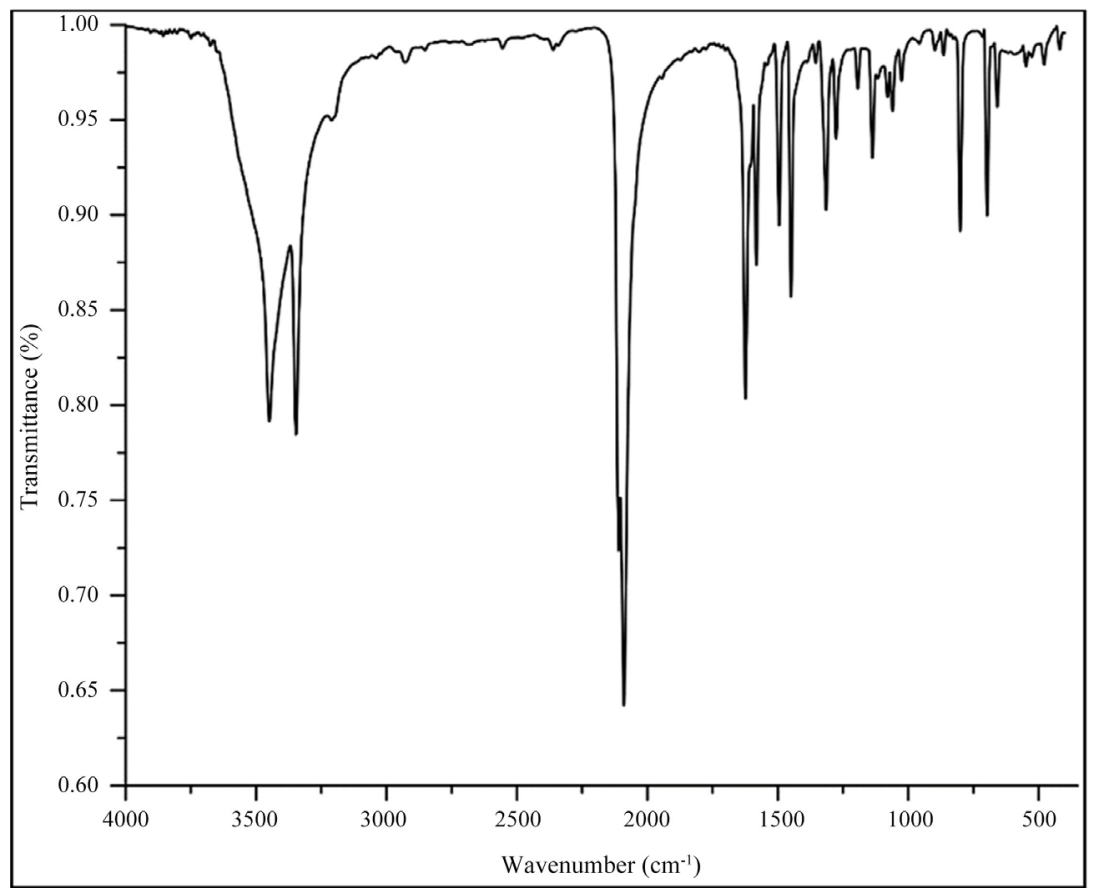

Figure 3. IR spectrum of the complex.

The experimental and theoretical values of some frequencies of the Zn-3-ampy complex are presented in Table 2. The values obtained at B3LYP/6-311++G(2d,2p) level of theory have been scaled by 0.944 for $\mathrm{NH}_{2}$ stretching and bending and $\mathrm{Zn}-\mathrm{N} 2$ while the others have been scaled by 1.007 [41]. The values obtained at wB97XD/6-311++G(2d,2p) level of theory were scaled by 0.957 (from CCCBDB listing of precalculated vibrational scaling factors (nist.gov)). As shown in Table 2 , the scaled and experimental frequencies are different, with the difference less than $44 \mathrm{~cm}^{-1}$. Therefore, there is a good agreement between the experimental and theoretical results.

The scaled frequencies obtained with wB97XD/6-311++G(2d,2p) are over estimated (particularly for $\mathrm{NH}_{2}$ ) compared to both experimental and B3LYP/6-311++G(2d,2p) values. However, it is important to note that the defference between the unscaled frequencies obtained at these two levels of theory is not large except for $\mathrm{NH}_{2}$.

\subsection{Thermal Analysis}

The TG and DTA curves for the complex are shown in Figure 4. Thermal analysis indicates that $\left[\mathrm{Zn}(3 \text {-ampy })_{2}(\mathrm{NCS})_{2}\right]$ decomposes in three steps. The first decomposition step, with a mass loss of $26.35 \%$, occurs from $220^{\circ} \mathrm{C}$ to $300^{\circ} \mathrm{C}$ and is attributed to the release of one 3-ampy molecule (theoretical $25.42 \%$ ). The second decomposition step from $300^{\circ} \mathrm{C}$ to $550^{\circ} \mathrm{C}(\Delta \mathrm{m}=25.65 \%)$ is attributed to the loss of a second molecule of 3-ampy to afford $\mathrm{Zn}(\mathrm{SCN})_{2}$. Further decomposition of this intermediate results in a residue of composition $\mathrm{ZnS}_{2}$ (residual mass: $35.46 \%$, theoretical: $34.62 \%$ ). This is accompanied by a broad exothermic DTA peak from $550^{\circ} \mathrm{C}$ to $800^{\circ} \mathrm{C}$. 
Table 2. Values $\left(\mathrm{cm}^{-1}\right)$ of some vibrational frequencies of $\mathrm{Zn}-3$-ampy.

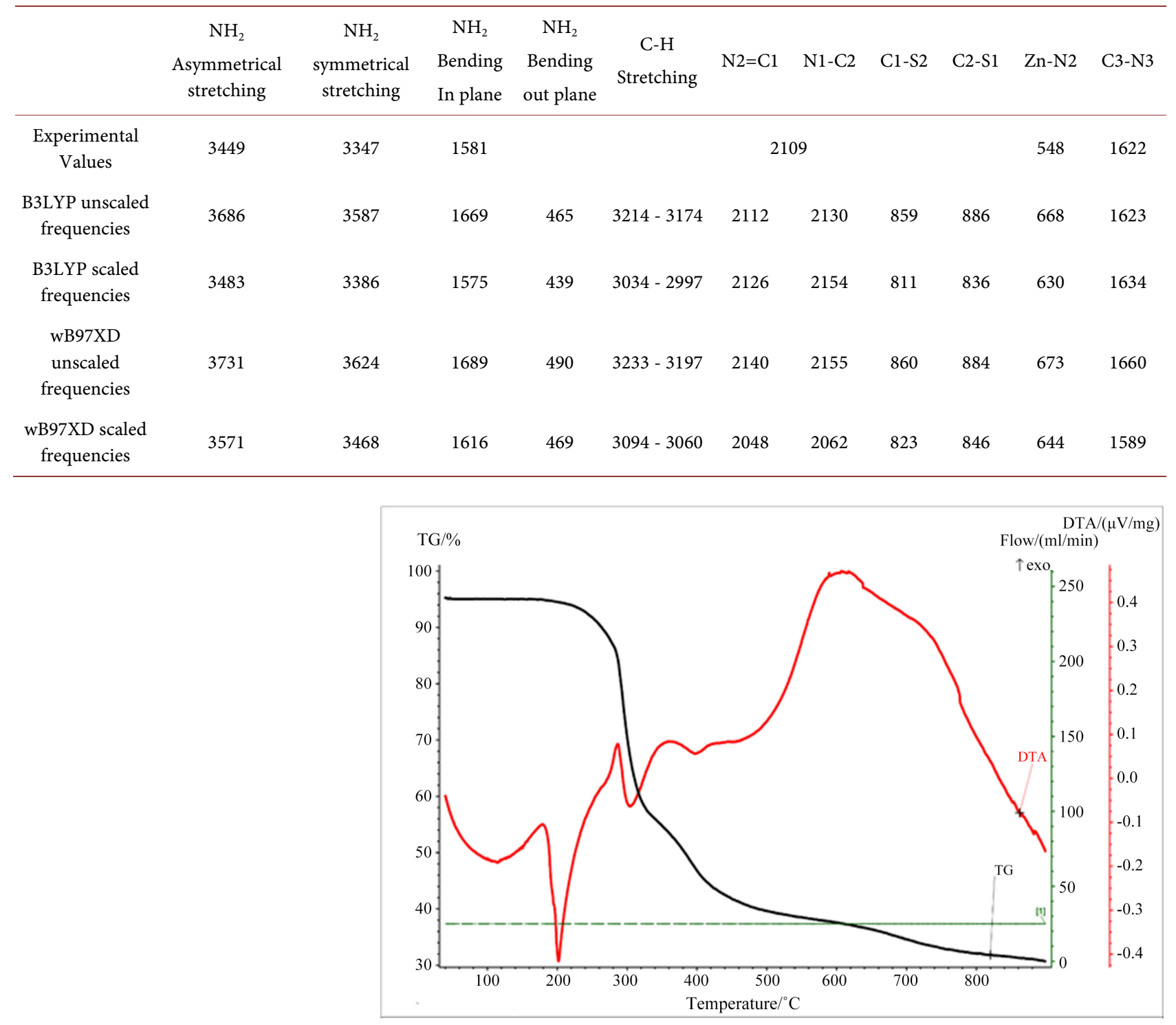

Figure 4. TG and DTA curves for the complex.

\subsection{Hirshfeld Surface Analysis}

The Hirshfeld surface (HS) [39] [42], defined as the electron density boundary surfaces between the molecules in a crystal, are useful to analyse and view the intermolecular contacts. Hirshfeld surface is mapped using the normalized contact distance $\left(d_{\text {norm }}\right)$, which is calculated using Equation (1).

$$
d_{\text {norm }}=\frac{d_{i}-r_{i}^{v d w}}{r_{i}^{v d w}}+\frac{d_{e}-r_{e}^{v d w}}{r_{e}^{v d w}} \text {. }
$$

The 3D $d_{n o r m}$ surface is used for identification of close intermolecular interactions which are mainly responsible for the molecular packing in the crystals. The sign of $d_{\text {norm }}$ can be used to characterise the intermolecular contact in the crystal. When $d_{\text {norm }}<0$, the intermolecular contacts are shorter than the van 
der Waals radii and they are referred to as close molecular interactions. When $d_{\text {norm }}>0$, intermolecular contacts are longer than the van der Waals radii and when $d_{\text {norm }}=0$ the intermolecular contacts are similar to the van der Waals radii. These three intermolecular interactions are identified on the Hirshfeld surfaces by their colour. Short contacts are represented by the red area, long contacts by the blue and the white area represents contacts with lengths equivalent to the sum of the van der Waal radii of the interacting atoms. The $d_{\text {norm }} 3 \mathrm{D}$ Hirshfeld surface of the synthesized molecule was calculated from its X-ray structure using Crystal Explorer 17.5 software and the results are presented in Figure 5. The close contact molecules have been included in the graph to allow the visualization of the atoms involved in the short contacts. The red spots on Figure 5 are observed around sulphur atoms of the thiocyanate and the two hydrogen atoms of the amine groups of the 3-ampy ligand. Therefore, all the close contacts in the crystal occur between sulphur and hydrogen atoms of the amine groups of different molecules. S-H interactions are then, the main interactions responsible for the molecular packing in the crystal. The distance between the sulphur and hydrogen atoms involved in the close contacts are $2.548 \AA$ and $2.816 \AA$. However, the intensity and the sizes of these red spots are not the same around the two sulphur atoms or the two hydrogen atoms. This indicates that the distance between the atoms involved in the short contact is directly proportional to the intensity and the size of the red spots of HS.

The 2D fingerprint plot [42] [43] can be derived from the 3D Hirshfeld surface. This is a plot of $d_{i}$ vs $d_{e}$ at each point of the 3D Hirshfeld surface and it provides a visual summary of the frequency of each combination of $d_{e}$ and $d_{i}$ across the surface of a molecule. The $2 \mathrm{D}$ fingerprint is used to quantitatively study at the same time, all the molecular contacts in the crystal. It has the advantage that it can be decomposed to highlight particular close contacts. This decomposition enables the separation of the contributions from different interaction types, which commonly overlap in the full fingerprint.

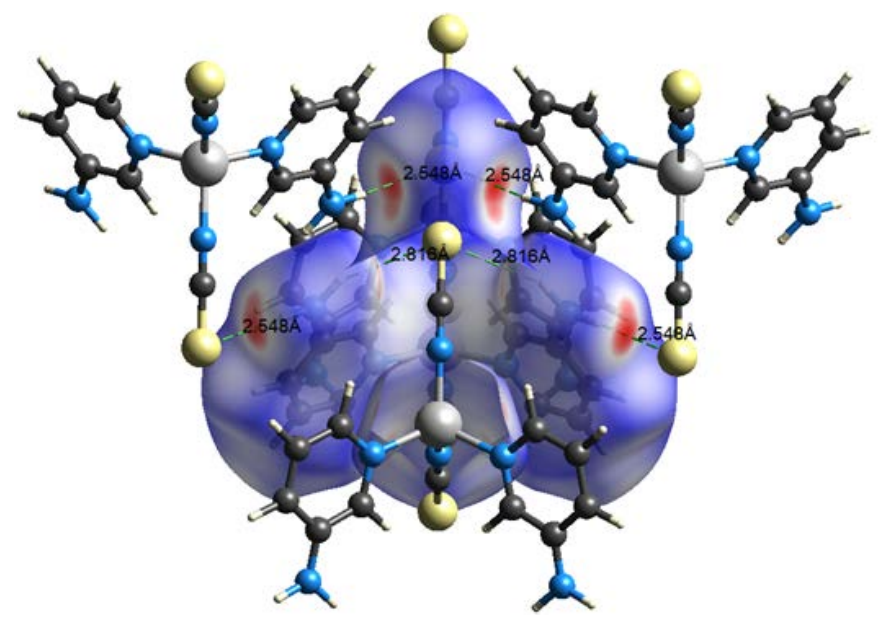

Figure 5. $d_{\text {norm }}$ 3D Hirshfeld surface of Zn-3-ampy with the close contact molecules. 
The decomposition of the 2D fingerprint of the studied molecule (presented in Figure 6) reveals that the main interaction that holds molecules together in the crystalline structure of the Zn-3-ampy are $\mathrm{X}---\mathrm{H}(\mathrm{X}=\mathrm{H}, \mathrm{C}, \mathrm{N}$ and S) interactions. These interactions represent $81.2 \%$ of all the intermolecular interactions in this crystal. However, their contribution decreases as follows: S-H $(30.2 \%)>\mathrm{H}-\mathrm{H}(24.3 \%)>\mathrm{C}-\mathrm{H}(20.6 \%)>\mathrm{N}-\mathrm{H}(6.1)$. It is important to note that, $\mathrm{C}-\mathrm{N}$ and C-S interactions have a non-negligible contribution of $8.4 \%$ and $4.3 \%$, respectively, to the packing of the crystal.

\subsection{Non-Covalent Interaction (NCI) Analysis}

Molecular packing into crystals involves a broad range of attractive and repulsive interactions. Thus, it is important to know if such interactions are attractive and therefore, stabilizing. NCI analysis in the unit cell was investigated using Multiwfn package and visualized by VMD molecular graphics viewer. Thus, due to the limitation of our computational resources, $\mathrm{NCI}$ analysis was performed on two of the four molecules in the unit cell of the complex. The dimer was optimized from the X-ray structure data using the wB97XD functional associated to the 6-31++G(d,p) basis set with ultrafine integral (see data in Tables S1 and S2, electronic supplementary material (ESM)). The wB97XD was chosen because of its capacity to handle weaker NCI [44]. The NCI, the reduced density gradient, was plotted as a function of the density (mapped as isosurfaces) over the molecule of interest. The nature of the specific interactions was identified as follows: strong attractive interaction is indicated in blue whereas red indicates a strong repulsive interaction. Weak interactions such as van der Waals interactions are highlighted by a green isosurface.

The NCI plot of the Zn-3-ampy complex (Figure 7) shows the presence of a very large green surface between the two molecules indicating that the two molecules are held together by van der Waals interactions. In addition, the small red surface at the centre of each pyridine ring indicates the steric interactions in this ring.

\subsection{Interaction Energy Calculation}

Crystal Explorer 17.5 software was also used to calculate and visualize the 3D energy framework along with intermolecular interaction energies. These interaction energies were calculated between a central molecule and the neighbouring molecules situated in a radius of $3.8 \AA$ around the central molecule. These neighbouring molecules were generated by applying crystallographic symmetry operations and 16 neighbour molecules were found. The B3LYP/6-31G(d,p) level of theory, as implemented in Crystal Explorer 17.5, was used to calculate the interaction energy between the central molecule and each of the 16 neighbours. The interaction energy between two molecules (Equation (2)) is a counterpoise corrected energy obtained as the sum of electrostatic energy $\left(E_{\text {ele }}\right)$, dispersion energy corrected by Grimme's D2 dispersion correction $\left(E_{\text {dis }}\right)$, polarization energy $\left(E_{p o l}\right)$, and exchange-repulsion energy $\left(E_{\text {rep }}\right)$ [45]. 

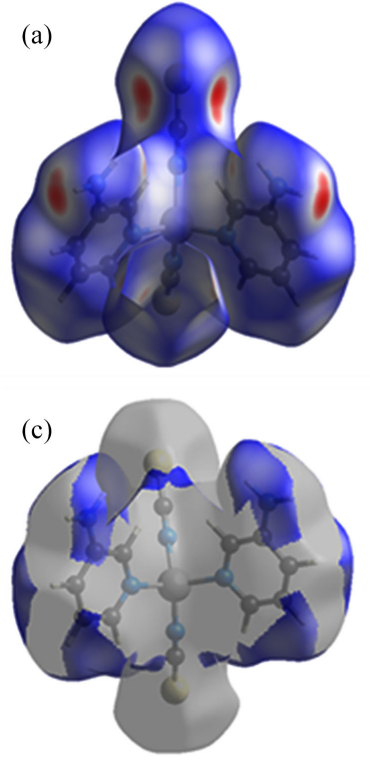

(e)

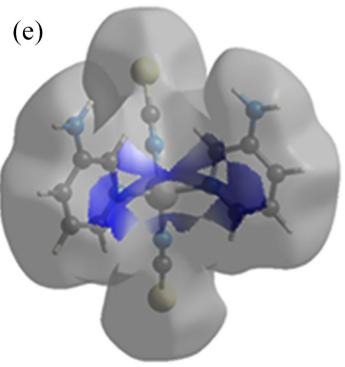

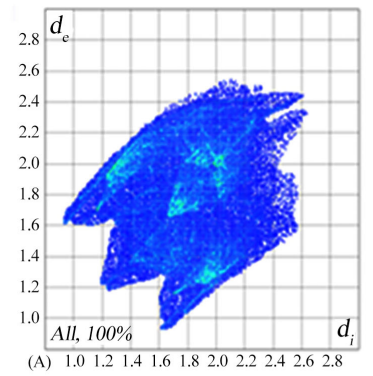
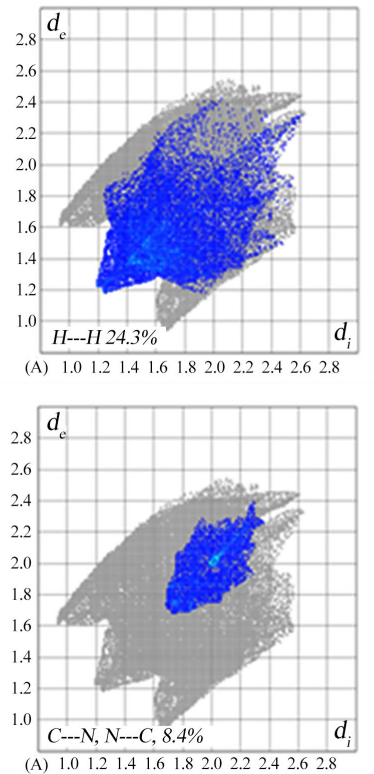
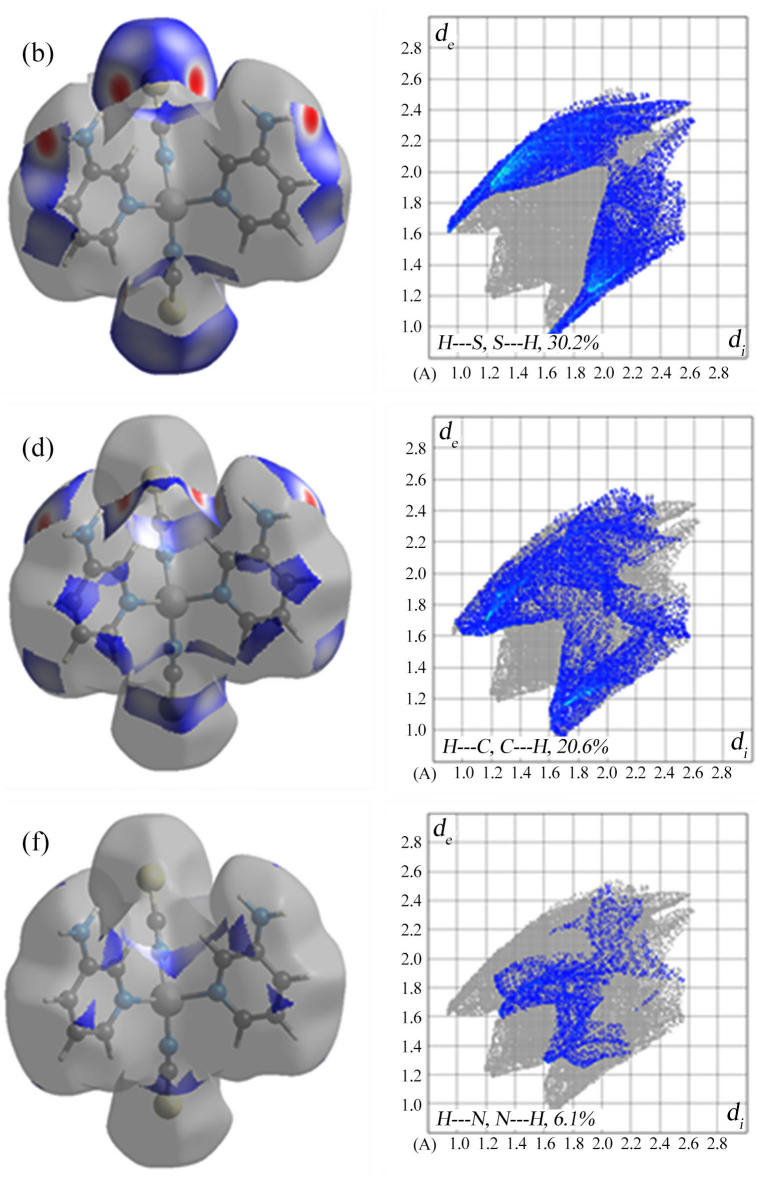

Figure 6. (a) $2 \mathrm{D}$ fingerprint plot for $\mathrm{Zn}-3$-ampy and fingerprint plot for the relative contribution of the (b) S---H/H---S, (c) $\mathrm{H}---\mathrm{H},(\mathrm{d}) \mathrm{C}---\mathrm{H} / \mathrm{H}---\mathrm{C},(\mathrm{e}) \mathrm{C}---\mathrm{N} / \mathrm{N}---\mathrm{C}$ and (f) N---H/H---N contacts associated to their 3D Hirshfeld surface.

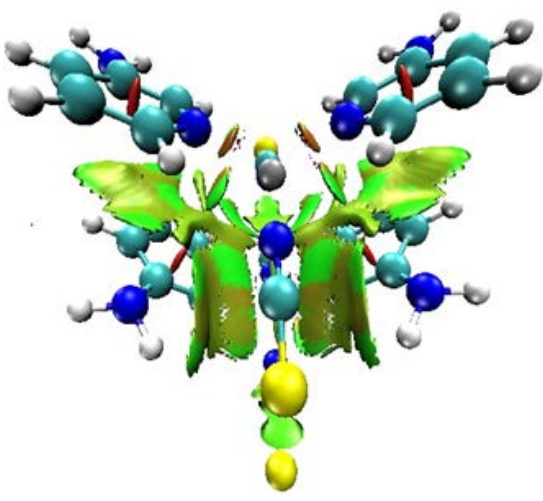

Figure 7. Plot of NCI isosurface for the complex.

$$
E_{\text {tot }}=E_{\text {ele }}+E_{\text {dis }}+E_{\text {pol }}+E_{\text {rep }}
$$

The value of interaction energy between the different pair of molecules and their four components are presented in Table 3 These energies have been scaled appropriately using for benchmarked energy models [45]. R represents the distance between the centroids (atomic means position) of two molecules and the $\mathrm{N}$ the number of molecules situated at the same distance $\mathrm{R}$ of the central molecule. 
Table 3. Value of electrostatic, dispersion, polarization and total interaction energies (in $\mathrm{kJ} / \mathrm{mol}$ ) and the distance between centroids (in $\AA$ ).

\begin{tabular}{ccccccc}
\hline $\mathrm{N}$ & $\mathrm{R}$ & $E_{\text {ele }}$ & $E_{\mathrm{pol}}$ & $E_{\mathrm{dis}}$ & $E_{\text {rep }}$ & $E_{\text {tot }}$ \\
\hline 4 & 11.06 & 5.3 & -2.5 & -5.7 & 1.2 & -0.5 \\
2 & 5.02 & -36.5 & -17.2 & -88.9 & 81.4 & -78.4 \\
2 & 8.89 & -80.5 & -25.1 & -35.4 & 63.3 & -95.4 \\
2 & 8.94 & -39.3 & -12.2 & -23.8 & 22.6 & -57.4 \\
4 & 9.33 & -29.6 & -7.0 & -11.7 & 10.7 & -40.1 \\
2 & 12.11 & 18.7 & -1.8 & -3.9 & 0.6 & 15.4 \\
\hline
\end{tabular}

These results indicate that, the interactions between the central molecule and its neighbours can be grouped in six categories. The molecules of each of these categories can be identified by their colours in Figure 8 .

The most important interaction energy $(-95.4 \mathrm{~kJ} / \mathrm{mol})$ is obtained between the molecules that have the strongest $\mathrm{S}-\mathrm{H}$ close contact with the central molecule. This interaction is dominated by the electrostatic component. The interaction between the yellow molecules and the central molecule is less than the previous one because of the proximity between the Zinc ions of these molecules. This $\mathrm{Zn}$-Zn repulsive interaction can also explain why S-H close contact involving yellow molecules is less important than those involving green molecules. The attraction between the yellow molecules and the central molecule is dominated by dispersion interactions. The interaction energy involving molecules that do not participate in close contacts can be attributed to their distance from the central molecule and are dominated by electrostatic attraction. The interactions between violet molecules and the central molecule are destabilizing interactions probably due to the symmetry between these molecules. For the studied cluster, the total electrostatic energy is $-161.9 \mathrm{~kJ} / \mathrm{mol}$, dispersion energy is -169.4 $\mathrm{kJ} / \mathrm{mol}$, polarization energy is $-65.8 \mathrm{~kJ} / \mathrm{mol}$, repulsion energy $179.8 \mathrm{~kJ} / \mathrm{mol}$ and the total interaction energy is $-217.3 \mathrm{~kJ} / \mathrm{mol}$. Therefore, electrostatic and dispersion interactions contribute equally to the molecular packing of the Zn-3-ampy molecules in the crystal. These observations substantiate the 3D framework energy diagrams (Figure 9) of the concerned molecules. However, this diagram shows that electrostatic and dispersion interactions are predominant in different directions. The size of the tube relating the centroid of two molecules is directly proportional to the intensity of the interaction of the molecules.

\subsection{Geometric Parameters}

The X-ray and theoretical geometry parameters for the complex are presented in Table 4. These results indicate that X-rays and theoretical geometry parameters are different and this difference is most important for bond angles. This observation is attributed to the fact that theoretical results are obtained from a single 
molecule in the vacuum while X-rays are obtained for a crystal which involves molecular interactions.

Table 4. Table type styles (Table caption is indispensable).

\begin{tabular}{|c|c|c|c|c|c|}
\hline & Exp & B3LYP & wB97xd & A & B \\
\hline N3-C3 & $1.342(2)$ & 1.336 & 1.331 & 1.335 & 1.337 \\
\hline N3-C7 & $1.338(2)$ & 1.341 & 1.335 & 1.339 & 1.339 \\
\hline $\mathrm{C} 3-\mathrm{C} 4$ & $1.394(2)$ & 1.400 & 1.394 & 1.400 & 1.399 \\
\hline C3-H3 & $0.95(2)$ & 1.082 & 1.083 & 1.087 & 1.086 \\
\hline C4-C5 & $1.395(2)$ & 1.400 & 1.395 & 1.399 & 1.401 \\
\hline $\mathrm{C} 4-\mathrm{N} 4$ & $1.366(2)$ & 1.381 & 1.379 & 1.385 & 1.380 \\
\hline $\mathrm{C} 5-\mathrm{C} 6$ & $1.378(2)$ & 1.385 & 1.382 & 1.388 & 1.387 \\
\hline C5-H5 & $0.93(2)$ & 1.082 & 1.082 & 1.087 & 1.086 \\
\hline C6-C7 & $1.379(2)$ & 1.387 & 1.383 & 1.388 & 1.389 \\
\hline C6-H6 & $0.96(2)$ & 1.080 & 1.080 & 1.084 & 1.084 \\
\hline C7-H7 & $0.94(2)$ & 1.080 & 1.081 & 1.085 & 1.084 \\
\hline N4-H2 & $0.84(2)$ & 1.007 & 1.006 & 1.013 & 1.009 \\
\hline N4-H1 & $0.82(2)$ & 1.007 & 1.004 & 1.009 & 1.008 \\
\hline $\mathrm{Zn}-\mathrm{N} 3$ & 2.017 & 2.119 & 2.094 & 2.088 & 2.081 \\
\hline $\mathrm{Zn}-\mathrm{N} 1$ & 1.929 & 1.914 & 1.912 & 1.902 & 1.917 \\
\hline $\mathrm{Zn}-\mathrm{N} 2$ & 1.955 & 1.939 & 1.935 & 1.921 & 1.918 \\
\hline $\mathrm{C} 2-\mathrm{N} 1$ & 1.162 & 1.180 & 1.176 & 1.183 & 1.180 \\
\hline $\mathrm{C} 2-\mathrm{S} 1$ & 1.619 & 1.613 & 1.610 & 1.612 & 1.610 \\
\hline $\mathrm{C} 1-\mathrm{N} 2$ & 1.161 & 1.179 & 1.175 & 1.182 & 1.183 \\
\hline $\mathrm{C} 1-\mathrm{S} 2$ & 1.624 & 1.618 & 1.616 & 1.615 & 1.614 \\
\hline N3-Zn-N3' & 111.35 & 64.9 & 49.6 & 107.2 & 117.5 \\
\hline N1-Zn-N2 & 119.29 & 133.4 & 134.3 & 133.6 & 135.9 \\
\hline N1-Zn-N3 & 110.01 & & & & \\
\hline $\mathrm{N} 2-\mathrm{Zn}-\mathrm{N} 3$ & 102.92 & & & & \\
\hline Zn-N1-C2 & 170.4 & 166.4 & 146.6 & 178.0 & 167.4 \\
\hline $\mathrm{Zn}-\mathrm{N} 2-\mathrm{C} 1$ & 170.7 & 150.0 & 140.4 & 169.4 & 160.9 \\
\hline Zn-N3-C3 & 118.1 & & & & \\
\hline N1-H7 & 2.923 & 2.815 & 2.790 & 2.743 & 2.646 \\
\hline N1-H7-C7 & 118.87 & 114.6 & 115.1 & 116.9 & 115.5 \\
\hline $\mathrm{N} 2-\mathrm{H} 3$ & 2.911 & 2.655 & 2.662 & 2.701 & 2.549 \\
\hline $\mathrm{N} 2-\mathrm{H} 3-\mathrm{C} 3$ & 110.35 & 118.1 & 118.0 & 113.4 & 116.0 \\
\hline N4-H1----S1 & 2.982 & & & \multicolumn{2}{|c|}{2.996} \\
\hline N4-H1----S1 & 155.19 & & & \multicolumn{2}{|c|}{137.9} \\
\hline
\end{tabular}

A and B refer to the two molecules of the dimer; A represents the molecule under the green surface and B the molecule on top of the green surface (Figure 7). 


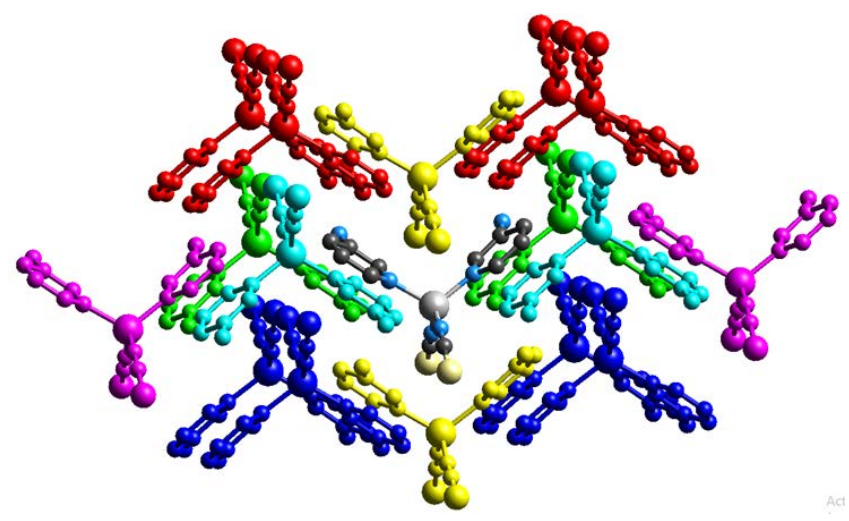

Figure 8. The colour code of the central molecule and its 16 neighbours according to their interaction energy.
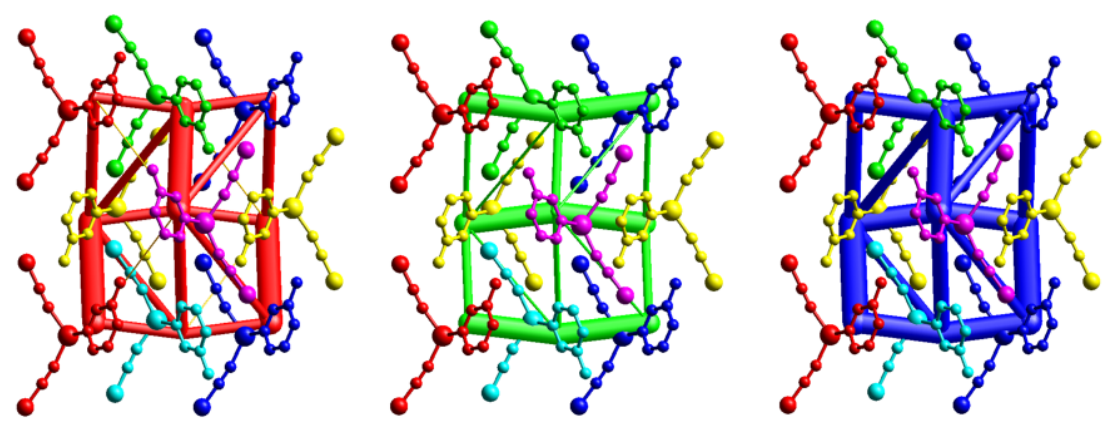

Figure 9. 3D energy framework diagram for separate electrostatic (left, red) and dispersion (middle, green) components of Zn-3-ampy and the total interaction energy (right, blue). The energy factor scale is 80 and the cut-off is $5.00 \mathrm{~kJ} / \mathrm{mol}$.

This result supports the fact that, the environment influences the properties of chemical species including their geometry parameters. However, linear regression analysis shows a linear correlation between the experimental and theoretical bond lengths. The regression coefficient and the standard deviations are $0.9869 / 0.053$ and $0.9876 / 0.051$ for B3LYP/6-311++G(2d,2p) and $w B 97 X D / 6-311++G(2 d, 2 p)$, respectively. Although the B3LYP is less robust than $\mathrm{wB} 97 \mathrm{XD}$, they produced similar results (data for xyz coordinates are in Tables S3 and S4, ESM; optimised geometry parameters are presented in Table S5, ESM). The results also reveal that $\mathrm{Zn}-\mathrm{N} 1$ and $\mathrm{Zn}-\mathrm{N} 2$ are shorter than $\mathrm{Zn}-\mathrm{N} 3$ probably because the thiocyanate is an anion and the charge transfer between this ligand and the metal is more important. In addition, the bond length between the $\mathrm{Zn}$ atom and the nitrogen atoms of the 3-ampy ligands (Zn-N3) are identical while the Zn-N1 and Zn-N2 are not. This is due to the van der Waals interaction between one of the hydrogen atoms of each amine group and the carbon atom of the thiocyanate group as revealed by the molecular diagram derived from NCIs analysis (Figure 7) of the electronic density of the concerned molecule. To confirm it, $\mathrm{Zn}(4-\mathrm{ampy})_{2}(\mathrm{NCS})_{2}$ have been optimized at $w B 97 X D / 6-311++G(2 d, 2 p)$ level of theory (see data in Tables S6 and S7, ESM) and the analysis of the results showed that Zn-N1(1.927 $\AA$ ) and Zn-N2 (1.926 ̊̊) are identical in Zn-4-ampy. This result confirms that 
the interaction between the carbon of the thiocyanate and the hydrogen of the amine groups is responsible for the difference between $\mathrm{Zn}-\mathrm{N} 1$ and $\mathrm{Zn}-\mathrm{N} 2$ bond length in Zn-3-ampy compound. These two bonds are shorter in Zn-4-ampy.

The complexes $\mathrm{Zn}$-3-ampy with chloride and bromide co-ligands were optimised at the B3LYP/6-311++G(d,p) level of theory [46]. Comparison of the coordinate bonds between the $\mathrm{Zn}$ atom and the pyridine nitrogen atom of 3-ampy in the compounds $\left(\mathrm{Zn}(3-\mathrm{ampy})_{2}(\mathrm{NCS})_{2}, \mathrm{Zn}(3-\mathrm{ampy})_{2} \mathrm{Cl}_{2}\right.$ and $\left.\mathrm{Zn}(3-\mathrm{ampy})_{2} \mathrm{Br}_{2}\right)$, indicates that the said bond lengths increase as follows: $\mathrm{Zn}(3 \text {-ampy })_{2}(\mathrm{NCS})_{2}$ $(2.017)<\mathrm{Zn}\left(3\right.$-ampy ${ }_{2} \mathrm{Cl}_{2}(2.144)<\mathrm{Zn}(3 \text {-ampy })_{2} \mathrm{Br}_{2}$ (2.152).

\subsection{Natural Bond Order (NBO) Analysis}

NBO [47] [48] analysis is a self-consistent theoretical framework for analysing the bonding nature of molecules and materials. It also analyses interaction between occupied orbitals (bond and lone pair) and unoccupied orbitals (anti-bonding and Rydberg orbitals) and between unoccupied orbitals. These interactions are interpreted as charge transfer between NBO donor and NBO acceptor or as the extension of the conjugation by electronic density delocalisation between the NBO donor and NBO acceptor. This type of interaction has the advantage to stabilize the molecule and the stabilisation energy associated $\left(E^{(2)}\right)$ with it is estimated by the second-order perturbation theory (Equation (3)). More intense is the interaction between the NBO donor and the NBO acceptor, greater is the extend of conjugation and higher is the $E^{(2)}$.

$$
E^{(2)}=q_{i} \frac{\left(F_{i, j}\right)^{2}}{\varepsilon_{j}-\varepsilon_{i}}
$$

The values of the stabilisation energies of some NBO orbital interactions of Zn-3-ampy have been determined in order to characterise its coordination bond and to identify the interactions that greatly contribute to the stability of the synthetized complex. The values $E^{(2)}$ higher than $5 \mathrm{~kJ} / \mathrm{mol}$ for some NBO donor and NBO acceptor are presented in Table 5.

Table 5. Value in $\mathrm{kcal} / \mathrm{mol}$ of stabilisation energy $\left(E^{(2)}\right)$ arising from de interaction between lone pair of chelating atoms and $\mathrm{Zn}(\mathrm{II})$ ion.

\begin{tabular}{cccccc}
\hline NBO donor & NBO acceptor & $E^{(2)}$ & NBO donor & NBO acceptor & $E^{(2)}$ \\
\hline $\mathrm{LP}(1) \mathrm{N} 21$ & $\mathrm{LP}^{\star}(6) \mathrm{Zn}$ & 40.40 & $\mathrm{LP}(1) \mathrm{N} 6$ & $\mathrm{LP}^{\star}(6) \mathrm{Zn}$ & 40.40 \\
$\mathrm{LP}(1) \mathrm{N} 21$ & $\mathrm{LP}(8) \mathrm{Zn}$ & 19.58 & $\mathrm{LP}(1) \mathrm{N} 6$ & $\mathrm{LP}^{\star}(8) \mathrm{Zn}$ & 19.56 \\
$\mathrm{LP}(1) \mathrm{N} 21$ & $\mathrm{LP}(9) \mathrm{Zn}$ & 28.34 & $\mathrm{LP}(1) \mathrm{N} 6$ & $\mathrm{LP}^{\star}(9) \mathrm{Zn}$ & 28.37 \\
$\mathrm{LP}(1) \mathrm{N} 4$ & $\mathrm{LP}(6) \mathrm{Zn}$ & 72.87 & $\mathrm{LP}(1) \mathrm{N} 5$ & $\mathrm{LP}^{\star}(6) \mathrm{Zn}$ & 62.13 \\
$\mathrm{LP}(1) \mathrm{N} 4$ & $\mathrm{LP}(7) \mathrm{Zn}$ & 62.24 & $\mathrm{LP}(1) \mathrm{N} 5$ & $\mathrm{LP}^{\star}(7) \mathrm{Zn}$ & 58.62 \\
$\mathrm{LP}(1) \mathrm{N} 4$ & $\mathrm{LP}$ & 12.40 & $\mathrm{LP}(1) \mathrm{N} 5$ & $\mathrm{LP}^{\star}(8) \mathrm{Zn}$ & 16.91 \\
\hline
\end{tabular}


The analysis of NBO reveals that the most important interaction between ligand and $\mathrm{Zn}^{2+}$ occurs mainly between the lone pairs of bonding atoms ( $s$ and $p$ orbitals) and $4 s$ and $4 p$ orbitals of $\mathrm{Zn}^{2+}$. The stabilisation energy $\left(E^{(2)}\right)$ of this charge transfer is the same for the two pyridine nitrogen atoms of the ring while it is different for the two nitrogen atoms of thiocyanate. The values due to metal-ligand charge transfer increase as follows $\mathrm{N}(3)<\mathrm{N}(2)<\mathrm{N}(3)$. The most important interaction occurs with $\mathrm{N}(1)$ while the less important is with $\mathrm{N}(3)$. This result is consistent with observations that the $\mathrm{N}(1)-\mathrm{M}$ bond is the shortest coordination bond in this molecule and the $\mathrm{N}(3)-\mathrm{M}$ bond is the longest one.

In this studied complex, there is also important charge transfer from $\mathrm{LP}^{*}$ and $\mathrm{RY}^{*}$ anti-bonding orbitals of metal ions with a stabilisation energy of 92 $\mathrm{kcal} / \mathrm{mol}$ of each ligand. This points out the importance of empty $s, p, d$ and $f \mathrm{Zn}$ orbitals adding to polarization and diffusion of the basis set, in the bonding process. NBO analysis also shows that, the delocalisation of the electronic density of the lone pair on sulphur atoms also play an important role in the stabilization process of this complex.

The analysis of NBO results also reveals that there is no orbital overlap between the metal ion and the chelating atoms of the ligand. Therefore, the bonding between the chelating atoms and the $\mathrm{Zn}(\mathrm{II})$ ion is mostly electrostatic interaction.

\subsection{Electronic Properties}

The HOMO and LUMO of the complex studied in this work are shown on Figure 10.

The HOMO of the complex is concentrated on the C-S and N-C bonds on one of the thiocyanate groups while the LUMO is distributed on the two pyridine cycles. The distribution of HOMO and LUMO indicates the nucleophilic and electrophilic part of the molecule, respectively. Energy values of these frontier molecular orbitals, the energy gap between these orbitals, the chemical potential, the global hardness and the dipole moment are used in quantum mechanics to describe the global reactivity of molecules. The data for the complex studied are presented in Table 6.

A high energy value for the HOMO indicates the tendency of the molecule to donate electrons and a low energy value for the LUMO shows a greater tendency to accept electrons. The energy values for the HOMO and LUMO of the complex studied indicates that it has the tendency to accept electrons than to donate. Compared to the B3LYP functional, the wB97XD functional overestimates the tendency of this molecule to accept electrons while it under estimates its tendency to donate electrons. The results (Table 6) also indicate that the wB97XD functional overestimates the chemical stability (high values of gap and $\eta$ ) of Zn-3-ampy and underestimates its polarizability (low dipole moment).

The Molecular electrostatic potential (MEP) [49] of the studied molecule (Figure 11) shows a blue area around the hydrogen atoms of the amine group, a yellow area around the sulphur and nitrogen atoms of the thiocyanate groups, 
and the rest of the surface is almost green. Then, the most electrophilic parts of the complex are the hydrogen atoms of the anime groups while the most nucleophilic are the sulphur and nitrogen atoms of the thiocyanate.

This result suggests that, the concerned molecule can act as hydrogen bond donor through hydrogen atoms and as hydrogen bond acceptor through sulphur and nitrogen atoms. However, comparing the intensity of the colours we can infer that, it acts as a good hydrogen donor but a poor hydrogen bond acceptor. The MEP of the complex also reveals that $\mathrm{S} 1$ and N1 are more nucleophilic than S2 and N2. This observation corroborates the distribution of the HOMO on the surface of the molecule and the atomic charges (Table 7). This result can be attributed to the fact that, S2 and N2 are involved in van der Waals contacts with the hydrogen atoms of the amine groups.
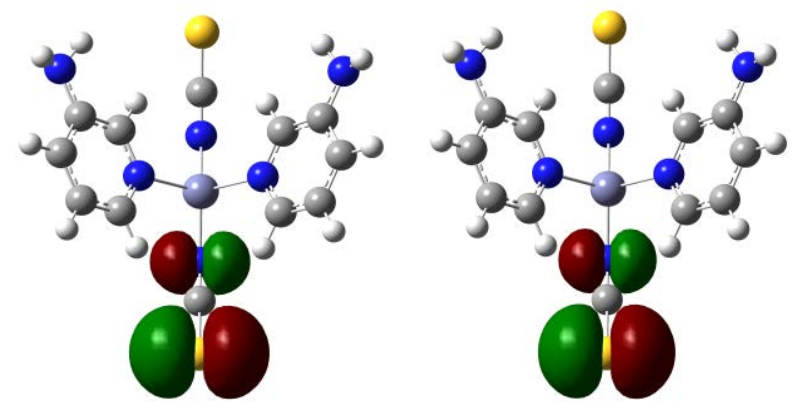

Figure 10. Representation of HOMO (left) and LUMO (right) distribution for the complex.
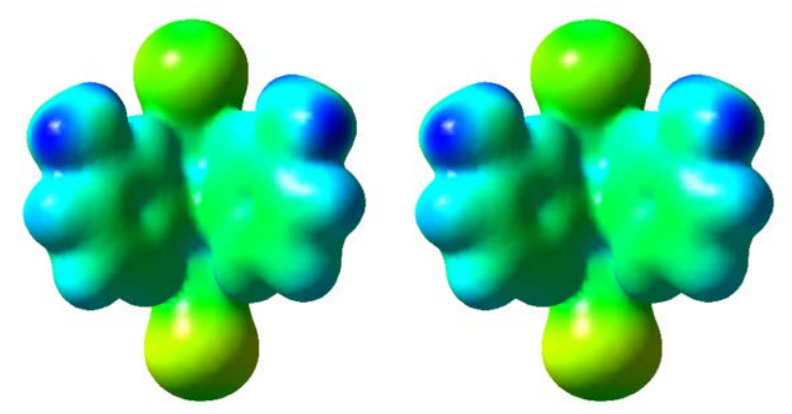

Figure 11. Molecular electrostatic potential map of the complex.

Table 6. Energy values of HOMO, LUMO, HOMO-LUMO gap, global hardness $(\eta)$, chemical potential $(\mu)$ (in $\mathrm{eV}$ ) dipole moment (in Debye) of the complex.

\begin{tabular}{ccccccc}
\hline & HOMO & LUMO & Gap & $\eta$ & $\mu$ & Dipole moment \\
\hline B3LYP & -5.85 & -2.12 & 3.73 & 1.86 & 3.98 & 12.61 \\
wB97XD & -8.03 & -0.20 & 7.82 & 3.91 & 4.12 & 11.59 \\
\hline
\end{tabular}

Table 7. Atomic charge obtained from natural population analysis.

\begin{tabular}{cccccccccc}
\hline Atoms & $\mathrm{N} 1$ & $\mathrm{~N} 2$ & $\mathrm{~N} 3$ & $\mathrm{~N} 4$ & $\mathrm{~S} 1$ & $\mathrm{~S} 2$ & $\mathrm{C} 2$ & $\mathrm{C} 1$ & $\mathrm{Zn}$ \\
\hline Charge & -0.756 & -0.731 & -0.529 & -0.793 & -0.218 & -0.194 & 0.195 & 0.182 & 1.216 \\
\hline
\end{tabular}




\section{Conclusion}

In the synthesised complex, the 3-ampy ligands coordinate to the $\mathrm{Zn}$ (II) ion through the pyridine $\mathrm{N}$-atoms. The $\mathrm{Zn}(\mathrm{II})$ ion in the complex adopts a tetrahedral environment comprising two pyridine $\mathrm{N}$-atoms for 3-aminopyridne and two nitrile $\mathrm{N}$-atoms from the thiocyanate. An interplay of weak intermolecular interactions extends the structure into three dimensions. The complex decomposes in three steps to afford a residue of composition $\mathrm{ZnS}_{2}$. Hirshfeld surface analysis indicates that the main interactions responsible for molecular packing in structure of the Zn-3-ampy are $\mathrm{X}---\mathrm{H}(\mathrm{X}=\mathrm{H}, \mathrm{C}, \mathrm{N}$ and $\mathrm{S})$ interactions in the order S-H $(30.2 \%)>\mathrm{H}-\mathrm{H}(24.3 \%)>\mathrm{C}-\mathrm{H}(20.6 \%)>\mathrm{N}-\mathrm{H}(6.1)$. The HOMO of the complex is concentrated on the $\mathrm{C}-\mathrm{S}$ bond of the thiocyanate group while the LUMO is distributed on the two pyridine cycles.

\section{Acknowledgements}

The authors are grateful to Dr. Peter Lönnecke of the Institute of the Inorganic Chemistry, Faculty of Chemistry and Mineralogy, Universität Leipzig, Germany for assistance with single crystal X-ray measurements.

\section{Conflicts of Interest}

The authors declare no conflicts of interest regarding the publication of this paper.

\section{References}

[1] Goher, M.A.S., Hafez, A.K., Abu-Youssef, M.A.M., Badr, A.M.A., Gspan, C. and Mautner, F.A. (2004) New Metal(II) Complexes Containing Monodentate and Bridging 3-Aminopyridine and Azido Ligands. Polyhedron, 23, 2349-2356. https://doi.org/10.1016/j.poly.2004.06.011

[2] Shurdha, E., Lapidus, S.H., Stephens, P.W., Moore, C.E., Rheingold, A.L. and Miller, J.S. (2012) Extended Network Thiocyanate- and Tetracyanoethanide-Based First-Row Transition Metal Complexes. Inorganic Chemistry, 51, 9655-9665. https://doi.org/10.1021/ic300804y

[3] Werner, J., Runčevski, T., Dinnebier, R., Ebbinghaus, S.G., Suckert, S. and Näther, C. (2015) Thiocyanato Coordination Polymers with Isomeric Coordination Networks-Synthesis, Structures, and Magnetic Properties. European Journal of Inorganic Chemistry, 2015, 3236-3245. https://doi.org/10.1002/ejic.201500473

[4] Suckert, S., Germann, L.S., Dinnebier, R.E., Werner, J. and Näther, C. (2016) Synthesis, Structures and Properties of Cobalt Thiocyanate Coordination Compounds with 4-(hydroxymethyl)pyridine as Co-Ligand. Crystals, 6, 38. https://doi.org/10.3390/cryst6040038

[5] Majumdar, D., Babu, M.S.S., Das, S., Mohapatra, C., Biswas, J.K. and Mondal, M. (2017) Syntheses, X-Ray Crystal Structures, Photoluminescence Properties, Antimicrobial Activities and Hirshfeld Surface of Two New Cd(II) Azide/Thiocyanate Linked Coordination Polymers. ChemistrySelect, 2, 4811-4822. https://doi.org/10.1002/slct.201700743

[6] Pandey, P., Kharediya, B., Elrez, B., Sutter, J.P., Bhargavi, G., Rajasekharan, M.V. and Sunkari, S.S. (2017) Ligand Directed Structural Diversity and Magnetism in 
Copper(II)-Azido Assemblies with Isomeric Aminopyridines: Synthesis, Structure, Magnetism and Theoretical Studies. Dalton Transactions, 46, 15908-15918. https://doi.org/10.1039/C7DT03115G

[7] Prananto, Y., Urbatsch, A., Moubaraki, B., Murray, K., Turner, D., Deacon, G. and Batten, S. (2017) Transition Metal Thiocyanate Complexes of Picolylcyanoacetamides. Australian Journal of Chemistry, 70, 516-528. https://doi.org/10.1071/CH16648

[8] Mashaly, M.M., Abd-Elwahabb, Z.H. and Faheim, A.A. (2004) Preparation, Spectral Characterization and Antimicrobial Activities of Schiff Base Complexes Derived from 4-Aminoantipyrine. Mixed Ligand Complexes with 2-Aminopyridine, 8-Hydroxyquinoline and Oxalic Acid and their Pyrolytical Products. Journal of the Chinese Chemical Society, 51, 901-915. https://doi.org/10.1002/jccs.200400135

[9] Lah, N. and Leban, I. (2005) Catena-Poly[[[bis(3-aminopyridine-[kappa]N)copper(II)]-di-[mu]-chloro]hydrate]. Acta Crystallographica Section E, 61, m1708m1710. https://doi.org/10.1107/S1600536805024578

[10] Wu, J.-Y., Feng, D.-M., He, H.-Y., Wang, Q.-X. and Zhu, L.-G. (2005) Poly[[[transbis(3-aminopyridine)copper(II)]-[mu]3-5-hydroxy-1,3-benzenedicarboxylato]mon ohydrate]. Acta Crystallographica Section E, 61, m1779-m1781. https://doi.org/10.1107/S1600536805025535

[11] Pan, W.L., Niu, X.L., Tang, W. and Hu, C.W. (2007) Bis(3-aminopyridine$\kappa \mathrm{N})$ diisothiocyanatozinc(II). Acta Crystallographica Section E, 63, m304-m305. https://doi.org/10.1107/S1600536806054791

[12] Yilmaz, V.T., Hamamci, S. and Kazak, C. (2007) (3-Aminopyridine- [kappa]N1)(saccharinato-[kappa]N)silver(I). Acta Crystallographica Section E, 63, m3000. https://doi.org/10.1107/S1600536807057248

[13] Yeh, C.-W., Jou, C.-H., Tsou, C.-H. and Suen, M.-C. (2012) Poly[[[mu]-(3-aminopyridine)-[kappa]2N:N'-[mu]-chlorido-chlorido(N,N'-dimethylformamide-[kappa]O)nickel(II)]N,N'-dimethylformamide monosolvate]. Acta Crystallographica Section E, 68, m1204-m1205. https://doi.org/10.1107/S1600536812036215

[14] Kartal, Z. (2016) Synthesis, Spectroscopic, Thermal and Structural Properties of $[\mathrm{M}(3$-aminopyridine $) 2 \mathrm{Ni}(\mu-\mathrm{CN}) 2(\mathrm{CN}) 2] \mathrm{n}(\mathrm{M}(\mathrm{II})=\mathrm{Co}$ and $\mathrm{Cu})$ Heteropoly Nuclear Cyano-Bridged Complexes. Spectrochimica Acta Part A, 152, 577-583. https://doi.org/10.1016/j.saa.2014.12.117

[15] Soliman, S.M. and Elsilk, S.E. (2017) Synthesis, Structural Analyses and Antimicrobial Activity of the Water Soluble 1D Coordination Polymer [Ag(3-aminopyridine)]ClO4. Journal of Molecular Structure, 1149, 58-68. https://doi.org/10.1016/j.molstruc.2017.07.072

[16] Dutta, D., Nashre-ul-Islam, S.M., Saha, U., Chetry, S., Guha, A.K. and Bhattacharyya, M.K. (2018) Structural Topology of Weak Non-Covalent Interactions in a Layered Supramolecular Coordination Solid of Zinc Involving 3-Aminopyridine and Benzoate: Experimental and Theoretical Studies. Journal of Chemical Crystallography, 48, 156-163. https://doi.org/10.1007/s10870-018-0723-5

[17] Mautner, F.A., Jantscher, P.V., Fischer, R.C., Torvisco, A., Reichmann, K. and Massoud, S.S. (2020) Syntheses, Structural Characterization, and Thermal Behaviour of Metal Complexes with 3-Aminopyridine as Co-Ligands. Transition Metal Chemistry, 46, 191-200. https://doi.org/10.1007/s11243-020-00436-2

[18] Yurdakul, Ö., Köse, D.A., Şahin, O. and Özer, D. (2021) Mn(II) and Co(II) Mixed-Ligand Coordination Compounds with Acesulfame and 3-Aminopyridine: Synthesis and Structural Properties. Journal of Coordination Chemistry, 1-13. https://doi.org/10.1080/00958972.2021.1888083 
[19] Dojer, B., Pevec, A., Jagodič, M., Kristl, M. and Drofenik, M. (2012) Three New Cobalt(II) Carboxylates with 2-, 3- and 4-Aminopyridine: Syntheses, Structures and Magnetic Properties. Inorganica Chimica Acta, 383, 98-104. https://doi.org/10.1016/j.ica.2011.10.056

[20] Krebs, C., Ceglarska, M. and Näther, C. (2021) Synthesis, Crystal Structures and Properties of Polymorphic and Isomeric Nickel(II)thiocyanate Coordination Compounds with 3-Bromopyridine as Coligand. Zeitschrift für anorganische und allgemeine Chemie, 647, 552-559. https://doi.org/10.1002/zaac.202000483

[21] Sanchez Montilva, O.C., Movilla, F., Rodriguez, M.G. and Di Salvo, F. (2017) Synthesis, Crystal Structure and Study of the Crystal Packing in the Complex Bis(4-aminopyridine-[kappa]N1)dichloridocobalt(II). Acta Crystallographica Section C, 73, 399-406. https://doi.org/10.1107/S2053229617004880

[22] Yuoh, A.C.B., Agwara, M.O., Yufanyi, D.M., Conde, M.A., Jagan, R. and Eyong, K.O. (2015) Synthesis, Crystal Structure, and Antimicrobial Properties of a Novel 1-D Cobalt Coordination Polymer with Dicyanamide and 2-Aminopyridine. International Journal of Inorganic Chemistry, 2015, Article ID: 106838. https://doi.org/10.1155/2015/106838

[23] Chimaine, F.T., Yufanyi, D.M., Yuoh, A.C.B., Eni, D.B. and Agwara, M.O. (2016) Synthesis, Crystal Structure, Photoluminescent and Antimicrobial Properties of a Thiocyanato-Bridged Copper(II) Coordination Polymer. Cogent Chemistry, 2, Article ID: 1253905. https://doi.org/10.1080/23312009.2016.1253905

[24] Das, A., Choudhury, S., Manna, P., Baxter, D., Helliwell, M. and Mukhopadhyay, S. (2011) Associative Combination of Lone Pair- $\pi, \pi-\pi$ and Anion- $\pi$ Interactions Observed in a Ternary System Comprising Mg(II)-malonate-2-aminopyridine-hexafluoridophosphate. Polyhedron, 30, 2121-2126. https://doi.org/10.1016/j.poly.2011.05.031

[25] Sheldrick, G.M. (2015) SHELXT-20xy. Acta Crystallographica Section A, 71, 3-8. https://doi.org/10.1107/S2053273314026370

[26] Linden, A. (2015) Chemistry and Structure in Acta Crystallographica Section C. Acta Crystallographica Section C, 71, 1-2. https://doi.org/10.1107/S2053229614026540

[27] Sheldrick, G.M. (2015) Serial Crystallography with X-Ray Free-Electron Laser Pulses. Acta Crystallographica Section A, 71, s1. https://doi.org/10.1107/S2053273315099982

[28] Macrae, C.F., Edgington, P.R., McCabe, P., Pidcock, E., Shields, G.P., Taylor, R., Towler, M. and van de Streek, J. (2006) Mercury: Visualization and Analysis of Crystal Structures. Journal of Applied Crystallography, 39, 453-457. https://doi.org/10.1107/S002188980600731X

[29] Engel, E. and Dreizler, R.M. (2011) Density Functional Theory: An Advanced Course. Springer, Berlin. https://doi.org/10.1007/978-3-642-14090-7

[30] Becke, A.D. (1988) Density-Functional Exchange-Energy Approximation with Correct Asymptotic Behavior. Physical Review A, 38, 3098-3100. https://doi.org/10.1103/PhysRevA.38.3098

[31] Becke, A.D. (1993) A New Mixing of Hartree-Fock and Local Density-Functional Theories. The Journal of Chemical Physics, 98, 1372-1377. https://doi.org/10.1063/1.464304

[32] Lee, C., Yang, W. and Parr, R.G. (1988) Development of the Colle-Salvetti Correlation-Energy Formula into a Functional of the Electron Density. Physical Review B, 37, 785-789. https://doi.org/10.1103/PhysRevB.37.785 
[33] Chai, J.-D. and Head-Gordon, M. (2008) Systematic Optimization of Long-Range Corrected Hybrid Density Functionals. The Journal of Chemical Physics, 128, Article ID: 084106. https://doi.org/10.1063/1.2834918

[34] Chai, J.-D. and Head-Gordon, M. (2008) Long-Range Corrected Hybrid Density Functionals with Damped Atom-Atom Dispersion Corrections. Physical Chemistry Chemical Physics, 10, 6615-6620. https://doi.org/10.1039/b810189b

[35] Ditchfield, R., Hehre, W.J. and Pople, J.A. (1971) Self-Consistent Molecular-Orbital Methods. IX. An Extended Gaussian-Type Basis for Molecular-Orbital Studies of Organic Molecules. The Journal of Chemical Physics, 54, 724-728. https://doi.org/10.1063/1.1674902

[36] Cramer, C.J. (2004) Essentials of Computational Chemistry: Theories and Models. Wiley, Hoboken.

[37] Frisch, M., Trucks, G., Schlegel, H., Scuseria, G., Robb, M., Cheeseman, J., Scalmani, G., Barone, V., Mennucci, B., Petersson, G., Nakatsuji, H., Caricato, M., Li, X., Hratchian, H., Izmaylov, A., Bloino, J., Zheng, G., Sonnenberg, J., Hada, M. and Fox, D. (2009) Gaussian 09 (Revision A02). Gaussian Inc., Wallingford.

[38] Contreras-Garcia, J., Yang, W. and Johnson, E.R. (2011) Analysis of Hydrogen-Bond Interaction Potentials from the Electron Density: Integration of Noncovalent Interaction Regions. The Journal of Physical Chemistry A, 115, 12983-12990. https://doi.org/10.1021/jp204278k

[39] Tan, S.L., Jotani, M.M. and Tiekink, E.R.T. (2019) Utilizing Hirshfeld Surface Calculations, Non-Covalent Interaction (NCI) Plots and the Calculation of Interaction Energies in the Analysis of Molecular Packing. Acta Crystallographica Section E, 75, 308-318. https://doi.org/10.1107/S2056989019001129

[40] Lu, T. and Chen, F. (2012) Multiwfn: A Multifunctional Wavefunction Analyzer. Journal of Computational Chemistry, 33, 580-592. https://doi.org/10.1002/jcc.22885

[41] Kashinski, D.O., Chase, G.M., Nelson, R.G., Di Nallo, O.E., Scales, A.N., VanderLey, D.L. and Byrd, E.F.C. (2017) Harmonic Vibrational Frequencies: Approximate Global Scaling Factors for TPSS, M06, and M11 Functional Families Using Several Common Basis Sets. The Journal of Physical Chemistry A, 121, 2265-2273. https://doi.org/10.1021/acs.jpca.6b12147

[42] Spackman, M.A. and McKinnon, J.J. (2002) Fingerprinting Intermolecular Interactions in Molecular Crystals. CrystEngComm, 4, 378-392. https://doi.org/10.1039/B203191B

[43] McKinnon, J.J., Mark, A.S. and Mitchell, A.S. (2004) Novel Tools for Visualizing and Exploring Intermolecular Interactions in Molecular Crystals. Acta Crystallographica Section B, 60, 627-668. https://doi.org/10.1107/S0108768104020300

[44] Mardirossian, N. and Head-Gordon, M. (2014) A 10-Parameter, Range-Separated Hybrid, Generalized Gradient Approximation Density Functional with Nonlocal Correlation, Designed by a Survival-of-the-Fittest Strategy. Physical Chemistry Chemical Physics, 16, 9904-9924. https://doi.org/10.1039/c3cp54374a

[45] Mackenzie, C.F., Spackman, P.R., Jayatilaka, D. and Spackman, M.A. (2017) Crystal Explorer Model Energies and Energy Frameworks: Extension to Metal Coordination Compounds, Organic Salts, Solvates and Open-Shell Systems. IUCrJ, 4, 575-587. https://doi.org/10.1107/S205225251700848X

[46] Akalin, E. and Akyuz, S. (2011) Experimental and Theoretical Vibrational Spectroscopic Investigation of $\mathrm{Zn}(\mathrm{II})$ Halide Complexes of 3-Aminopyridine and 3-Chloropyridine. Journal of Molecular Structure, 993, 390-396. 
https://doi.org/10.1016/j.molstruc.2011.01.060

[47] Weinhold, F., Landis, C.R. and Glendening, E.D. (2016) What Is NBO Analysis and How Is It Useful? International Reviews in Physical Chemistry, 35, 399-440. https://doi.org/10.1080/0144235X.2016.1192262

[48] Weinhold, F. (2012) Natural Bond Orbital Analysis: A Critical Overview of Relationships to Alternative Bonding Perspectives. Journal of Computational Chemistry, 33, 2363-2379. https://doi.org/10.1002/jcc.23060

[49] Rathi, P.C., Ludlow, R.F. and Verdonk, M.L. (2020) Practical High-Quality Electrostatic Potential Surfaces for Drug Discovery Using a Graph-Convolutional Deep Neural Network. Journal of Medicinal Chemistry, 63, 8778-8790.

https://doi.org/10.1021/acs.jmedchem.9b01129 